\title{
Desigualdade e Desenvolvimento: a hipótese de Kuznets é válida para os municípios brasileiros? ${ }^{1}$
}

Laura Correa de Barros"

Fábio Augusto Reis Gomes**

Resumo: Este trabalho investigou a validade da hipótese de Kuznets sobre desigualdade e desenvolvimento para os municípios do Brasil nos anos de 1991 e 2000. A desigualdade foi medida pelos índices de Gini e L de Theil. As medidas de desenvolvimento foram a renda per capita e a razão entre a população urbana e a população total. Os resultados foram ambíguos: algumas especificações rejeitaram a hipótese de Kuznets e outras não; porém, todos os modelos apresentaram um poder explicativo muito fraco. Portanto, a capacidade da hipótese de Kuznets para explicar a desigualdade entre os municípios brasileiros é bastante limitada.

Palavras-chave: Desigualdade, Desenvolvimento Econômico, Hipótese de Kuznets.

Abstract: This paper analyzed the validity of Kuznets' inequality-development hypothesis for Brazilian cities in 1991 and 2000. Inequality was measured by the Gini and the Theil-L indexes. The measures for development were the per capita income and the ratio between urban and total population. The results were ambiguous: some specifications rejected the Kuznets' hypothesis while other showed the opposite result; however, the models' goodness of fit was extremely poor. Therefore, the ability of Kuznets' hypothesis to explain inequality among Brazilian cities is exceptionally limited.

Keywords: Inequality, Economic Development, Kuznets' Hypothesis.

JEL Classification: C23; D31; O10; O15.

1 Gostaríamos de agradecer a Juliana Riani, Cláudio Shikida, Cleomar Gomes, Márcio Antônio Salvato e aos pareceristas anônimos pelos comentários. No entanto, os isentamos de qualquer equívoco cometido neste artigo.

* Fundação João Pinheiro / Escola de Governo Professor Paulo Neves de Carvalho - MG. Email: lauracbarros@yahoo.com.br

** Autor para correspondência. Ibmec São Paulo. Rua Quatá, 300, 4 Andar, Sala 422, Vila Olímpia. São Paulo, SP, Brasil - CEP: 04546-042. Tel: (11) 4504-2776. E-mail: fabioarg@isp.edu.br 


\section{Introdução}

Kuznets (1955) é freqüentemente citado na literatura sobre desigualdade de renda devido à sua hipótese de que, inicialmente, a desigualdade aumenta com o desenvolvimento econômico, atingindo um nível máximo e, posteriormente, diminui, o que resulta em uma curva com formato de U invertido. O argumento de Kuznets é baseado na migração rural-urbana, devido, essencialmente, à hipótese de que a área urbana é mais produtiva do que a rural. Mais especificamente, Kuznets (1955) analisa a transição do modo de produção agrícola para industriais e urbanos, partindo de certos pressupostos: a renda per capita média da população rural é, em geral, menor do que a da população urbana; o percentual da renda do setor agrícola sobre a renda total diminui ao longo do tempo; e a desigualdade na população rural é menor do que na população urbana. Daí, o autor conclui que a diferença relativa na renda per capita entre populações urbana e rural tende a ser ampliada porque a produtividade urbana cresce mais rapidamente do que a agrícola, o que acarretaria em aumento da desigualdade de renda entre a área rural e urbana. Com a migração rural-urbana, inicialmente a desigualdade aumentaria e, posteriormente, se reduziria com a concentração de pessoas na área urbana. Observando somente dados dos Estados Unidos, Inglaterra e Alemanha, Kuznets (1955) sugere, então, que a distribuição de renda tenderia a melhorar a partir de um determinado estágio de desenvolvimento do país. O autor também verificou que a renda per capita desses países aumenta de forma significativa ao longo dos anos. Assim, a redução na desigualdade ocorreria pelo aumento da parcela da renda per capita de grupos "mais baixos" em ritmo maior do que de grupos "mais altos".

O Brasil está entre os países mais desiguais do mundo. Segundo dados dos Indicadores de Desenvolvimento Mundial de 2007, do Banco Mundial, dentre 127 países para os quais há valores disponíveis, o Brasil possui o $11^{\circ}$ maior coeficiente de Gini, de valor igual a 57.0 (conforme pesquisa realizada em 2004). Esta situação é agravada pela dificuldade de se reverter a concentração de renda. Desta forma, este tema é de extrema importância, especialmente no que diz respeito à implementação de políticas públicas, pois possui interferência nos âmbitos social e econômico.

O objetivo deste trabalho é investigar a validade da hipótese de Kuznets para 5.507 municípios brasileiros. Para tanto, são utilizados os dados do Atlas do Desenvolvimento Humano do Brasil (2003) referentes aos anos censitários de 1991 e 2000. São utilizados métodos 
paramétricos para estimar a relação entre desigualdade e desenvolvimento, e são implementadas análises de robustez na medida em que são consideradas diversas formas funcionais, duas medidas de desigualdade - índices de Gini e L de Theil -, e duas medidas de desenvolvimento - renda per capita e fração da população urbana. Esta fração serve de proxy para a migração rural-urbana, já que é nesta migração que reside o cerne do argumento de Kuznets (1955).

Os estudos sobre a curva de Kuznets podem ser agrupados de acordo com a sua metodologia, pois enquanto alguns usam modelos não-paramétricos, ${ }^{2}$ a maioria dos autores usa modelos paramétricos, ${ }^{3}$ sendo esta a opção deste trabalho. Dentro desta abordagem, algumas formas funcionais são mais usuais, como um polinômio do $2^{\circ}$ grau usado por Barro (2000), Thornton (2001), Bagolin, Gabe e Ribeiro (2004), Jacinto e Tejada (2004) e Salvato et alli (2006). Porém, segundo List e Gallet (1999), para níveis muito altos de renda, depois de caracterizado o $\mathrm{U}$ invertido de Kuznets, o desenvolvimento pode implicar em um novo aumento da desigualdade, justificado pela migração da indústria para o setor de serviços. Para contemplar esta possibilidade, esses autores utilizam um polinômio do $3^{\circ}$ grau. Por fim, Anand e Kanbur (1993) partiram dos pressupostos de Kuznets e encontram analiticamente a forma funcional a ser testada para cada medida de desigualdade utilizada.

A literatura nacional que se propõe a estudar a curva de Kuznets a partir de dados municipais inclui Salvato et alli (2006), que estudaram os municípios de Minas Gerais, Jacinto e Tejada (2004), que estudaram municípios da região nordeste, e Bêrni, Marquetti e Kloeckner (2002) e Bagolin, Gabe e Ribeiro (2004), que analisaram municípios do Rio Grande do Sul. Em geral, estes estudos encontram evidências favoráveis à hipótese de U invertido. Em relação a estes trabalhos, este estudo apresenta as seguintes diferenças e contribuições: i) a análise dos municípios do Brasil; ii) uma análise de robustez, ao considerar diversas formas funcionais, ${ }^{4}$ duas medidas de desigualdade e duas medidas de desenvolvimento. De fato, o uso da proxy de migração constitui uma inovação mesmo ao considerar a literatura internacional. Por último, é importante ressaltar que os estudos entre países são mais comuns do que os estudos de um mesmo país, apesar

2 Mushinski (2001), Bêrni, Marquetti e Kloeckner (2002) utilizam um método não paramétrico enquanto Lin et al. (2006) empregam um método semi-paramétrico.

3 Ver Anand e Kanbur (1993), List e Gallet (1999), Barro (2000), Mushinski (2001), Thornton (2001), Bagolin, Gabe e Ribeiro (2004), Jacinto e Tejada (2004) e Salvato et alli (2006).

4 É importante ressaltar que nenhum dos artigos citados sobre o Brasil utilizou a forma funcional proposta por List e Gallet (1999). 
de Anand e Kanbur (1993) argumentarem que cada país pode apresentar um processo de Kuznets particular ou até mesmo inexistente, sendo fundamental estudar os países de forma individual.

Após as estimações, os resultados sugerem que as estimativas apresentam certo grau de sensibilidade à mudança da medida de desigualdade utilizada e à forma funcional do modelo. Os modelos com polinômio de $2^{\circ}$ grau e forma funcional de Anand e Kanbur (1993) - para a renda - não rejeitam a hipótese de Kuznets, porém, apresentam um baixo poder explicativo. No caso do polinômio do $3^{\circ}$ grau, a hipótese de Kuznets não é rejeitada apenas quando se usa o Gini em conjunto com a razão entre população urbana e população total, mas novamente o poder explicativo do modelo deixa a desejar. Em suma, é no mínimo questionável a capacidade da hipótese de Kuznets de explicar a desigualdade de renda entre os municípios brasileiros.

Além desta introdução, este trabalho está estruturado da seguinte forma: a segunda seção apresenta uma síntese da literatura internacional e nacional; a metodologia empírica utilizada é descrita na terceira seção; na quarta seção, são apresentados os resultados e, por fim, a última seção apresenta as principais conclusões.

\section{Curva de Kuznets}

\subsection{Motivações Teóricas para curva de Kuznets}

Kuznets (1955) investigou o caráter e as causas de mudanças de longo prazo na distribuição pessoal da renda, buscando delinear os fatores relevantes em relação ao histórico e às tendências evolutivas da desigualdade de renda. Os pressupostos centrais de Kuznets são: a renda per capita média da população rural é menor do que a da população urbana, o percentual da renda do setor agrícola sobre a renda total diminui ao longo do tempo, e a desigualdade de renda na população rural é menor do que na população urbana. Assim, o autor concluiu que a migração da população rural para as áreas urbanas cria dois grupos com nível de renda distinta, acentuando-se o grau de desigualdade da sociedade como um todo. Após uma migração considerável da população rural para a região urbana, a desigualdade passa a cair, pois grande parte da população passa a receber uma renda mais alta no setor industrial e urbano. Portanto, a transição da área rural para a urbana geraria uma relação entre desigualdade e desenvolvimento no formato de um U invertido.

Este U invertido não seria "simétrico", uma vez que, ao final da migração, a desigualdade não seria igual àquela observada no início 
deste processo, dada a hipótese que a área urbana é mais desigual do que a rural. Kuznets argumenta que o declínio da desigualdade com o crescimento econômico ocorreria porque os indivíduos que nascem em centros urbanos são mais capazes de obter maiores rendas em relação a indivíduos "imigrantes" de setores agrícolas ou de fora do país. Outra possibilidade citada por Kuznets (1955) é o aumento gradual da eficiência dos indivíduos devido ao maior tempo que passam no cenário urbano.

Kuznets complementa sua análise argumentando que, em estágios mais iniciais do crescimento, é provável a observação de condições pouco favoráveis à população mais pobre, tal como um crescimento mais rápido do que o da população rica, o que contribuiria para acentuar a desigualdade neste período. Já o declínio da desigualdade em estágios mais avançados da industrialização pode ser justificado também pelo aumento do poder político dos mais pobres. Estes fariam pressões políticas por melhor distribuição da renda.

Em um estudo mais recente, Barro (2000) afirma que análises sobre a relação entre desigualdade e crescimento econômico podem ser feitas de acordo com diversas teorias, agrupadas em quatro áreas principais: imperfeições do mercado de crédito, decisões do eleitor mediano, distorções nas taxas de poupança e tensões sociais.

As imperfeições do mercado de crédito, devido a problemas de informações assimétricas e limitações impostas por instituições legais, afetam negativamente e, mais acentuadamente, os mais pobres, aumentando a desigualdade. Porém, com o desenvolvimento da economia e a ampliação deste mercado, o acesso dos pobres ao mercado de crédito pode ser aumentado, reduzindo a desigualdade. Voitchovsky (2005) também argumenta que os ricos, por possuírem mais recursos, são menos afetados por imperfeições de mercado.

Nos modelos de economia política, em geral, o resultado de uma eleição depende do eleitor mediano (MELTZER; RICHARD, 1981). Assim, se o eleitor mediano é pobre, venceria o candidato que propõe políticas mais redistributivas. Portanto, quanto maior a desigualdade, maior a probabilidade de ocorrer uma política redistributiva que reduza a desigualdade. Voitchovsky (2005) corrobora esta análise ao referenciar a realização de redistribuição por meio de cobranças de impostos e de outras formas também baseadas nas preferências do eleitor mediano.

Em um ambiente de elevada desigualdade, as tensões sociais podem aumentar e os mais pobres podem tornar-se mais propensos a cometer crimes e a apresentar outros comportamentos não-produtivos. Neste caso, se a proteção aos direitos de propriedade é deficiente, não 
há incentivo para realizar investimentos e o crescimento é prejudicado. Dessa forma, uma maior desigualdade tende a reduzir a produtividade e, conseqüentemente, o crescimento. Reativamente, o governo pode aumentar as transferências de recursos para as camadas mais pobres e, com isso, reduzir a desigualdade e seus efeitos negativos sobre o crescimento. De fato, Acemoglu e Robinson (2002) desenvolveram um modelo teórico no qual inicialmente o poder político está concentrado em uma elite rica, até que aconteça uma reforma política resultante da mobilização social. $\mathrm{O}$ modelo sugere que a evolução da desigualdade depende da existência ou ausência de ameaças de revolução e, em alguns cenários, é possível observar a ocorrência da curva de Kuznets.

De todo modo, uma redistribuição dos ricos para os pobres, causada ou não pelas decisões do eleitor mediano, pode, em tese, diminuir a taxa de poupança da economia e, conseqüentemente, reduzir o crescimento econômico. Neste caso, haveria uma redução da desigualdade às custas de um crescimento econômico menor.

Segundo Glaeser (2005), a curva de Kuznets ocorre devido a fatores econômicos e políticos. Com o avanço da industrialização, o governo assumiria uma postura mais ativa quanto à redistribuição da renda, fazendo com que a desigualdade diminua com o desenvolvimento, um fator mencionado por Kuznets (1955). Outros fatores também se tornariam relevantes, tais como o tamanho do governo, o aumento do capital humano, as políticas direcionadas para cidadãos mais pobres e a transformação da força de trabalho agrária em trabalhadores industriais agrupados que podem se organizar.

Por fim, Voitchovsky (2005) argumenta que maior crescimento e maior desigualdade são constatados em estruturas econômicas que oferecem maiores recompensas à habilidade e ao esforço. Assim, esses tipos de incentivos podem exercer influências importantes em toda a distribuição de renda, e não apenas no seu topo. Em geral, a alta desigualdade está relacionada à criminalidade entre os pobres e ao rent-seeking ${ }^{5}$ entre os ricos, que tem efeitos deletérios sobre o crescimento. Enquanto no primeiro caso coexistem alta desigualdade e elevado crescimento, no segundo caso tem-se alta desigualdade com baixo crescimento.

\subsection{Estudos empíricos}

Diversos estudos buscaram avaliar a validade da hipótese de Kuznets por meio de diferentes abordagens, sendo a maioria delas

5 Para maiores detalhes sobre rent-seeking, ver Tullock (1967) e Krueger (1974). 
baseadas em modelo paramétricos. A revisão de alguns desses estudos é útil para elucidar o modelo implementado neste trabalho.

A forma mais simples de se testar a hipótese de Kuznets é através da estimação do modelo:

$$
I=\alpha_{0}+\alpha_{1} D+\alpha_{2} D^{2}+\varepsilon, \text { sendo } \frac{d^{2} I}{d D^{2}}=2 \alpha_{2}
$$

em que I é uma medida qualquer de desigualdade e $D$ é uma medida de desenvolvimento econômico. A condição para se encontrar uma curva côncava é $\alpha_{2}<0 .{ }^{6}$ Vários autores basearam-se nesta abordagem. Por exemplo, Barro (2000) analisou dados em painel de vários países de 1965 a 1995, usando o Gini e a taxa de crescimento da renda. $\mathrm{O}$ autor não refutou a hipótese de Kuznets, mas afirmou que a curva em $U$ invertido tem relevância estatística limitada e pouco poder explicativo. ${ }^{7}$

Thornton (2001) afirma que a evidência empírica favorável à hipótese de U invertido não é clara, pois na literatura seria comum o uso de amostras reduzidas ${ }^{8}$ e de dados que não guardam comparabilidade. Para contornar estes problemas, o autor utilizou dados comparáveis de 96 países, provenientes do estudo de Deininger e Squire (1996). Usando o modelo (1) com dados de Gini e (ln) PIB, o autor não rejeita a hipótese de Kuznets de U invertido.

List e Gallet (1999) estudaram 71 países no período de 1961 a 1992, usando o índice de Gini e a renda per capita, considerando um polinômio do $3^{\circ}$ grau:

$$
I=\alpha_{0}+\alpha_{1} D+\alpha_{2} D^{2}+\alpha_{3} D^{3}+\varepsilon, \text { sendo } \frac{d^{2} I}{d D^{2}}=2 \alpha_{2}+6 \alpha_{3} D
$$

A condição para se encontrar uma curva côncava é $D<-\alpha_{2} / 3 \alpha_{3}$. Se a renda for superior a este valor, a relação entre desigualdade $\mathrm{e}$ desenvolvimento volta a ser crescente. De fato, isto ocorreu no estudo de List e Gallet (1999). Assim, após certo nível de renda per capita, o nível de desigualdade volta a subir. Os autores sugeriram que este resultado deve-se à transição de uma base manufatureira em direção ao setor de serviços.

6 A condição de concavidade é necessária para validar a hipótese de Kuznets, mas não é suficiente. Em outras palavras, uma função pode ser côncava e não ter o formato de $\mathrm{U}$ invertido.

7 Em uma versão ampliada da curva de Kuznets, Barro (2000) considera outras variáveis explicativas, como consumo do governo sobre PIB, índice sobre democracia e taxa de inflação e, com isso, conclui que as evidências sugerem que a desigualdade desacelera o crescimento em países pobres e acelera o crescimento em países ricos.

8 O próprio Kuznets (1995) analisa apenas Estados Unidos, Inglaterra e Alemanha. 
Mushinski (2001) utilizou dados do censo decenal de 1990 de 212 regiões nativo-americanas dos Estados Unidos, considerando um polinômio de quarto grau. $\mathrm{O}$ autor usou a renda per capita dessas regiões como medida de desenvolvimento, e o coeficiente de Gini como medida de desigualdade. No entanto, seus resultados não rejeitaram a hipótese de Kuznets. ${ }^{9}$

Anand e Kanbur (1993) propuseram outra forma funcional para testar a hipótese de Kuznets. Partindo dos pressupostos de Kuznets (1955), os autores mostraram analiticamente qual seria a relação entre cada medida de desigualdade e o nível de renda. Foram consideradas 6 medidas diferentes de desigualdade, entre elas o Gini e o L de Theil, empregadas neste trabalho. No caso do índice de Gini tem-se:

$$
G=\beta_{0}+\beta_{1} R+\beta_{2}^{G}(1 / R), \text { sendo } \frac{d^{2} G}{d R^{2}}=\frac{2 \beta_{2}^{G}}{R^{3}}
$$

em que $\mathrm{G}$ é o índice de Gini e $\mathrm{R}$ é a renda. Encontra-se uma curva côncava somente quando $\beta_{2}^{G}<0$. No caso do índice 1 de Theil tem-se:

$$
L=\beta_{0}+\beta_{1} R+\beta_{2}^{L} \ln (R), \text { sendo } \frac{d^{2} L}{d R^{2}}=-\frac{\beta_{2}^{L}}{R^{2}}
$$

em que $L$ é o índice $L$ de Theil. A curva é côncava se $\beta_{2}^{L}>0$. Nesta abordagem, a validade da curva de Kuznets não depende apenas de se encontrar uma curva em U invertido; seria necessário também encontrar tal curva usando estas especificações.

Com base nestas formas funcionais, Anand e Kanbur (1993) analisaram dados de anos variados entre 1958 a 1972 de 60 países (desenvolvidos e em desenvolvimento) e uma subamostra de 40 países (em desenvolvimento). A hipótese investigada era a de que esse grupo de países segue o mesmo processo de Kuznets, a qual foi rejeitada.

Voitchovsky (2005) usou dados do Luxembourg Income Study ${ }^{10}$ sobre a distribuição de renda (dados sobre Gini e PIB per capita) de uma amostra de 25 países $^{11}$ industrializados para os anos de 1975, 1980, 1985, 1990, 1995. Os resultados obtidos sugerem que, no topo da distribuição, quanto maior a desigualdade, maior o crescimento, enquanto na parte mais baixa da distribuição de renda, quanto maior a desigualdade, menor é o crescimento, relações já observadas anteriormente por Barro (2000). ${ }^{12}$

9 Mushinski (2001) também utiliza um estimador não-paramétrico e, neste caso, a hipótese de Kuznets continua não sendo rejeitada.

10 Ver http://www.lisproject.org/.

11 A autora reconhece os problemas de estimação para uma amostra reduzida.

12 De fato, empiricamente, essa autora investiga o impacto da desigualdade sobre o crescimento. 
Usando dados de diversos países nos anos de 1970, 1980 e 1990, Lopez (2006) dinvestigou a estabilidade da relação entre crescimento econômico e desigualdade ao longo do tempo, analisando o impacto de variações na $(\ln )$ renda sobre variações no $(\ln )$ Gini. Os resultados indicaram que a desigualdade não aumentou com o crescimento econômico nas décadas de 70 e 80, mas tais variáveis apresentaram correlação positiva na década de 90 , na proporção de $1 \%$ de crescimento para 3\% a $4 \%$ de aumento no índice de Gini, levando em conta as mudanças ocorridas durante as décadas. Possíveis justificativas dadas pelo autor para essa última constatação são a liberalização econômica e as mudanças tecnológicas.

Bagolin, Gabe e Ribeiro (2004) investigaram a hipótese de Kuznets para os municípios brasileiros do Estado do Rio Grande do Sul nos anos de 1970, 1980 e 1991, utilizando o modelo (1) com o índice L de Theil e a renda per capita. ${ }^{13}$ Ao estimar um modelo em painel os autores não refutaram a curva com formato de U invertido para municípios gaúchos. Porém, o $\mathrm{R}^{2}$ encontrado foi igual a 0,3299 apenas. ${ }^{14,15}$

Jacinto e Tejada (2004) investigaram a hipótese de Kuznets para os municípios do Nordeste do Brasil no período de 1970 a 1991. Utilizando o índice $\mathrm{L}$ de Theil e a renda per capita, os autores estimaram em painel um polinômio do $2^{\circ}$ grau e a forma funcional proposta por Anand e Kanbur (1993). Nos dois casos, a hipótese de $\mathrm{U}$ invertido não foi rejeitada e os $\mathrm{R}^{2}$ foram bastante similares, no primeiro modelo igual a 0,20 e no segundo igual a 0,23.

Salvato et alli (2006) estimaram o modelo na forma quadrática para os municípios de Minas Gerais. Foram utilizados os índices de Gini e L de Theil, além da renda per capita municipal nos anos de 1991 e 2000. Os resultados não rejeitaram a hipótese de Kuznets, tanto no caso do Gini quanto no caso do L de Theil. Porém, o $\mathrm{R}^{2}$ obtido é igual a 0,1151 no primeiro caso e 0,0373 no segundo caso.

Por fim, Dentre Bêrni, Marquetti e Kloeckner (2002) avaliaram a relação entre a desigualdade de renda em 1991 e o nível de renda per capita em 1990 dos 333 municípios do Rio Grande do Sul, por meio de um método não paramétrico (regressão local). Os autores consideraram diferentes setores de produção, uma vez que a região possui uma importante tradição agrícola. Esses autores não rejeitaram a

13 Os autores trabalham com a base dados completa e, posteriormente, excluem os municípios com renda per capita muito acima da média.

14 Os autores também fizeram as estimativas retirando os outliers e, neste caso, o R2 tornouse 0,3655 .

15 Bagolin, Gabe e Ribeiro (2004), Jacinto e Tejada (2004) e Salvato et alli (2006) analisaram também cada cross-section separadamente. Porém, são apresentados apenas os resultados do modelo em painel. 
hipótese de Kuznets, mas apresentaram ressalvas, particularmente quanto ao setor agropecuário, no qual a curva com formato de $\mathrm{U}$ invertido não foi observada. Como o argumento de Kuznets (1955) é baseado na migração rural-urbano, dividir a amostra justamente entre estes dois setores é um procedimento questionável e pode ser a causa de não se encontrar a curva de Kuznets.

A partir desta síntese, é possível fazer duas observações. Primeiro, apesar do argumento de Kuznets ser baseado na migração rural-urbana, a literatura, pelo menos a mencionada acima, não explorou este canal diretamente. Segundo, a proposta de List e Gallet (1999) ainda não foi implementada pela literatura nacional. Estas lacunas são, em larga medida, cobertas neste trabalho.

\section{Metodologia Empírica}

\subsection{Base de dados}

Os dados utilizados nas análises empíricas foram extraídos do Atlas do Desenvolvimento Humano no Brasil (2003) e referem-se a 5.507 municípios brasileiros nos anos de 1991 e 2000. Os dados já são ajustados para as emancipações municipais ocorridas no período e os valores monetários são expressos em reais de primeiro de agosto de 2000 (corrigidos pelo Índice Nacional de Preços ao Consumidor INPC), o que assegura a comparabilidade entre os municípios ao longo do tempo.

Segundo Vanhoudt (2000), estudos internacionais estão particularmente sujeitos a erros de medida que decorrem de diferenças nos questionários usados para a coleta de dados ou outros fatores que interferem na aferição de indicadores de desigualdade em diversos países. Neste sentido, uma das vantagens do estudo proposto é a probabilidade reduzida de erros de medida. Como medidas de desigualdade de renda, são usados índices municipais de Gini e L de Theil. As medidas de desenvolvimento utilizadas são renda per capita em $\mathrm{R} \$ 1000,00$ - daqui em diante, Renda -, e a razão entre a população urbana e a população total - daqui em diante, Urbana.

A estatística descritiva de cada uma das variáveis é apresentada na tabela 1. Em média, os valores dos índices L de Theil e Gini aumentaram em aproximadamente $6 \%$, indicando uma piora na distribuição de renda municipal de 1991 para 2000. As medidas de dispersão (desvio-padrão e coeficiente de variação) tenderam a diminuir, o que evidencia uma redução da dispersão da desigualdade de 1991 para 2000. A tabela 1 reporta ainda que a média da variável Renda 
aumentou e as medidas de dispersão (desvio-padrão e coeficiente de variação) da mesma não foram substancialmente alteradas. Sobre a variável Urbana, a média aumentou de 1991 para 2000, como esperado. Essa razão apresentou também uma ligeira redução do desviopadrão e uma considerável redução do coeficiente de variação de cerca de 0,52 para 0,40, o que reflete um movimento de concentração ainda crescente na área urbana, neste período. É importante destacar que existem municípios totalmente urbanos (máximo para Urbana é 1) e outros totalmente rurais (mínimo para Urbana é zero). Assim, apesar da dimensão temporal dos dados cobrir apenas um período de 10 anos, a amplitude da Renda e Urbana em cada cross-section é bastante elevada. Em outras palavras, além de agregar a dimensão temporal, há considerável variabilidade entre o nível de desenvolvimento (Renda e Urbana) dos municípios, em cada ano. Esta variabilidade é fundamental, pois para identificar a curva de Kuznets é preciso ter municípios em diferentes estágios de desenvolvimento.

É importante ressaltar que a correlação entre Renda e Urbana é aproximadamente 0,61 em 1991 e 0,54 em 2000, o que indica que a suposição de Kuznets (1955) de que a área urbana possui uma renda per capita maior parece adequada. Porém, estas variáveis não são tão similares e o uso da renda pode não ser adequado para avaliar a validade da curva de Kuznets. Em outras palavras, os modelos econométricos que empregam a renda podem chegar a resultados distintos daqueles que empregam uma medida direta de migração. A investigação desta possibilidade é uma das contribuições deste artigo.

Tabela 1. Estatística descritiva

\begin{tabular}{|c|c|c|c|c|c|c|}
\hline $\begin{array}{c}\text { Medidas/ } \\
\text { Variáveis }\end{array}$ & Ano & Média & Máximo & Mínimo & $\begin{array}{c}\text { Desvio- } \\
\text { Padrão }\end{array}$ & $\begin{array}{c}\text { Coeficiente de } \\
\text { Variação }\end{array}$ \\
\hline \multirow{2}{*}{ L de Theil } & 1991 & 0,49 & 1,18 & 0,2 & 0,12 & 0,24 \\
& 2000 & 0,52 & 1,27 & 0,19 & 0,11 & 0,21 \\
\hline \multirow{2}{*}{ Gini } & 1991 & 0,53 & 0,79 & 0,35 & 0,06 & 0,11 \\
\hline \multirow{2}{*}{ Renda } & 2000 & 0,56 & 0,82 & 0,36 & 0,06 & 0,1 \\
\hline & 1991 & 0,12 & 0,58 & 0,02 & 0,07 & 0,59 \\
\hline & 2000 & 0,17 & 0,96 & 0,03 & 0,1 & 0,56 \\
\hline \\
\cline { 2 - 7 }
\end{tabular}

Fonte: Elaboração dos autores.

\subsection{Modelo econométrico}

É possível utilizar um modelo econométrico que explora a característica de painel dos dados através da seguinte especificação:

$$
I_{i t}=X_{i t} \phi+u_{i t}
$$


em que $\mathrm{I}_{\mathrm{it}}$ é a medida de desigualdade, $\mathrm{X}_{\mathrm{it}}$ agrupa todas as variáveis explicativas, $u_{i t}$ é o erro, $t$ é o índice de tempo e $i$ é o indexador dos municípios. Se $u_{i t}$ é um erro aleatório, a equação (5) pode ser estimada pelo Método de Mínimos Quadrados estendido para o caso de painel, abreviadamente POLS. ${ }^{16}$ Porém, o termo de erro pode conter um efeito idiossincrático municipal. Neste caso, a especificação torna-se:

$$
I_{i t}=X_{i t} \phi+u_{i t}, u_{i t}=\tau_{i}+\varepsilon_{i t}
$$

O termo $\tau_{i}$ representa o efeito particular de cada município $i$, sendo constante ao longo do tempo. Duas abordagens são possíveis. A primeira, denominada modelo de Efeito Aleatório (EA), é a que supõe que $\tau_{i}$ não é correlacionado com os demais regressores. A segunda, chamada modelo de Efeito Fixo (EF), não assume esta hipótese. No primeiro caso, a estimação da equação (6) via OLS ${ }^{17}$ é consistente. Porém, quando $s \neq t, \mathrm{E}\left(u_{i t} u_{i s}\right)=\operatorname{var}\left(\tau_{i}\right)$ é diferente de zero e o OLS deixa de ser eficiente. Daí a necessidade de estimar a equação (2) via GLS. ${ }^{18}$ Por outro lado, a estimação do modelo de EF é feita do seguinte modo: retira-se a média da equação (6) no tempo, subtraindo-a da própria equação (6), isto é:

$$
I_{i t}-\bar{I}_{i}=\left(X_{i t}-\bar{X}_{i}\right) \phi+\varepsilon_{i t}-\bar{\varepsilon}_{i}
$$

em que $\bar{I}_{i}=\sum_{t} I_{i t} / T$ e $\bar{\varepsilon}_{i}=\sum_{t} \varepsilon_{i t} / T$. Note que o efeito idiossincrático é eliminado uma vez que $\tau_{\mathrm{i}}-\tau_{\mathrm{i}}=0$. Assim, pode-se estimar a equação (6.2) sem maiores problemas. Este procedimento é que dá origem ao estimador de EF, como discutido por Wooldridge (2001). Alguns autores referem-se a este procedimento como estimador within, e consideram como EF o uso de variáveis dummies por unidade $i$ para captar o efeito idiossincrático municipal. ${ }^{19}$ No entanto, será seguida a abordagem de Wooldridge (2001), pois como o próprio autor argumenta, a discussão crucial é se o termo idiossincrático é ou não correlacionado com os regressores, sendo esta a maior distinção entre o modelo de EF e o modelo de EA.

Portanto, as estimativas serão realizadas usando três estimadores de Painel: POLS, EF e EA. Para escolher entre estes dois últimos

16 Do inglês, Pooled Ordinary Least Squares.

17 Do inglês, Ordinary Least Squares.

18 Do inglês, Generalized Least Squares.

19 Neste caso, é comum usar o termo LSDV, do inglês Least Squares Dummy Variable. 
modelos, é aplicado o teste de Hausman, cuja hipótese nula é a não existência de correlação entre o componente idiossincrático e as variáveis explicativas, isto é, a validade do modelo de EA.

Finalmente, as seguintes especificações são usadas:

$$
\begin{gathered}
I_{i t}=\alpha_{0}+\alpha_{1} D_{i t}+\alpha_{2} D_{i t}^{2}+\delta D T+u_{i t} \\
I_{i t}=\alpha_{0}+\alpha_{1} D_{i t}+\alpha_{2} D_{i t}^{2}+\alpha_{3} D_{i t}^{3}+\delta D T+u_{i t} \\
G_{i t}=\beta_{0}+\beta_{1} R_{i t}+\beta_{2}^{G}\left(1 / R_{i t}\right)+\delta D T+u_{i t} \\
L_{i t}=\beta_{0}+\beta_{1} R_{i t}+\beta_{2}^{L} \ln \left(R_{i t}\right)+\delta D T+u_{i t}
\end{gathered}
$$

As equações (7) e (8) são estimadas usando o Gini e o L de Theil e as variáveis explicativas Renda e Urbana. ${ }^{20}$ Porém, as equações (9) e (10) são específicas para cada tipo de medida de desigualdade e foram derivadas por Anand e Kanbur (1993) apenas Renda, não sendo aplicáveis à Urbana. Além disso, todos os modelos incluem uma dummy de tempo (DT) igual a 1 em 2000 e zero em 1991.

Dentre todas as especificações mencionadas, apenas o polinômio de $3^{\circ}$ grau, (8), é capaz de testar a hipótese de List e Gallet (1999), pois dependendo dos valores de $\alpha_{2}$ e a $\alpha_{3}$, pode-se obter uma curva inicialmente côncava e, posteriormente, convexa. As demais especificações são mais restritas, pois não contemplam esta possibilidade. No caso do polinômio do segundo grau, (7), se $\alpha_{2}<0\left(\alpha_{2}>0\right)$ a curva estimada é côncava (convexa) em todo domínio. No caso da especificação (9), se $\beta_{2}^{G}<0\left(\beta_{2}^{G}>0\right)$ a curva estimada é sempre côncava (convexa). Por fim, no caso da especificação (10), caso $\beta_{2}^{L}$ $>0\left(\beta_{2}^{L}<0\right)$ a curva estimada é sempre côncava (convexa). Nesta perspectiva, a especificação (8) é preferida, pois é a única capaz de investigar tanto a hipótese de Kuznets (1955) quanto a de List e Gallet (1999).

\section{Resultados}

A tabela 2 apresenta os resultados do modelo (7) quando D é a Renda. ${ }^{21}$ Todas as regressões com o L de Theil atenderam à condição

20 As correlações entre $D, D 2$ e $D 3$ são bastante elevadas, tanto no caso da Renda quanto no caso da Urbana. Por isso, para evitar problemas de multicolinearidade não foram utilizados polinômios de grau maior.

21 As tabelas 2 a 6 são apresentadas no Apêndice. 
de concavidade $\left(\alpha_{2}<0\right)$, indicando que não se pode rejeitar a hipótese de Kuznets. Porém, o $\mathrm{R}^{2}$ dos modelos é baixo e, no caso, do modelo de EF, indicado pelo teste de Hausman, seu valor é de apenas 0,0821 . No caso do Gini, a condição de concavidade $\left(\alpha_{2}<0\right)$ é atendida apenas pelo modelo de EF - indicado pelo teste de Hausman -, cujo $\mathrm{R}^{2}$ é igual a 0,2202. No POLS e EA, o coeficiente da Renda ao quadrado é não significativo.

A tabela 3 mostra os resultados para o modelo (8) quando D é a Renda. Nas regressões com o L de Theil, a condição $D_{\text {it }}<-\alpha_{2} / 3 \alpha_{3}$ não é atendida para todos os municípios, independentemente do estimador usado. Assim, em todos os casos, rejeita-se a hipótese de Kuznets. Além disso, o $\mathrm{R}^{2}$ do modelo de $\mathrm{EF}$ - escolhido pelo teste de Hausman - é apenas 0,1042 e, neste caso, 20 municípios em 1991 e 88 em 2000 estão na parte convexa da curva estimada. No caso do Gini, os resultados são similares, sendo a hipótese de Kuznets rejeitada com os três estimadores. No modelo de EF - sugerido pelo teste de Hausman - o $\mathrm{R}^{2}$ atinge 0,236 e o número de municípios que estão parte convexa da curva estimada é igual à 28 em 1991 e 145 em 2000.

A tabela 4 apresenta os resultados das regressões para as formas funcionais de Anand e Kanbur (1993), ou seja, especificações (9) e (10). Os resultados indicam que, no caso do $\mathrm{L}$ de Theil, todas as regressões atendem à condição de concavidade $\left(\beta_{2}^{\mathrm{L}}>0\right)$ não sendo rejeitada a hipótese de Kuznets (1955). No entanto, o $\mathrm{R}^{2}$ do modelo de EF - indicado pelo teste de Hausman - é de apenas 0,1568. No caso do Gini, a condição de concavidade $\left(\beta_{2}^{G}>0\right)$ é sempre atendida. Porém, mais uma vez, o poder explicativo dos modelos é bastante limitado; por exemplo, o modelo de EF - escolhido pelo teste de Hausman - apresenta $R^{2}$ igual a 0,3093 apenas.

A tabela 5 apresenta os resultados do modelo (7) quando D é a variável Urbana. Todas as regressões com o L de Theil atenderam à condição de concavidade $\left(\alpha_{2}<0\right)$, indicando que não se pode rejeitar a hipótese de Kuznets. Porém, o $\mathrm{R}^{2}$ dos modelos são também baixos e, no caso, do modelo de EF - indicado pelo teste de Hausman - seu valor é de apenas 0,0844. No caso do Gini, a condição de concavidade $\left(\alpha_{2}<0\right)$ é atendida em todos os modelos, diferentemente dos resultados obtidos com a Renda (tabela 2). $\mathrm{O} \mathrm{R}^{2}$ do modelo de EF - indicado pelo teste de Hausman - é igual a 0,2607.

A tabela 6 mostra os resultados para o modelo (8) quando D é a variável Urbana. Nas regressões com o L de Theil, a condição $\mathrm{D}_{\mathrm{it}}<$ $-\alpha_{2} / 3 \alpha_{3}$ é atendida nos modelos POLS e EA, mas não é atendida no modelo EF, sugerido pelo teste de Hausman. $\mathrm{O} \mathrm{R}^{2}$ do modelo de $\mathrm{EF}$ é apenas 0,0858 e, neste caso, 595 municípios em 1991 e 954 em 
2000 estão na parte convexa da curva estimada. No caso do Gini, a condição de concavidade é atendida nos modelos POLS e EF, mas não no modelo EA. No modelo de EF - sugerido pelo teste de Hausman - , o $\mathrm{R}^{2}$ atinge 0,2614 .

Em geral, há uma série de restrições ao uso do $\mathrm{R}^{2}$ para análise de modelos em painel, pois neste contexto tal medida não possui a interpretação usual feita com dados cross-sections, podendo exceder a unidade, inclusive. No entanto, quando o modelo escolhido é o $\mathrm{EF}$ - o que ocorreu em todos os casos -, o $\mathrm{R}^{2}$ within possui a interpretação usual, pois ele é simplesmente o $R^{2}$ da regressão (6.2), na qual o efeito idiossincrático foi "eliminado". Neste caso, podemos analisá-lo, sem maiores problemas, como uma medida de ajuste do modelo e, conforme mencionado na discussão dos resultados, a capacidade explicativa do modelo deixa a desejar, por esta medida. Esta conclusão é corroborada pela análise visual, apresentada a seguir, das estimativas de $X_{i t} \hat{\phi}$ da equação (6.1), obtidas por meio do estimador de EF. O interesse particular no termo $X_{i t} \hat{\phi}$ ocorre porque ele contém a informação sobre a curva de Kuznets. Por exemplo, no caso do polinômio do $2^{\circ}, X_{i t}$ contém a constante, a renda e a renda ao quadrado, enquanto $\hat{\phi}$ contém as estimativas de seus coeficientes, ou seja, a informação sobre a concavidade da curva estimada.

As figuras 1 a 4 apresentam os resultados das regressões das tabela 2 a 4 com o estimador de EF. A figura 1 mostra o índice $\mathrm{L}$ de Theil em 1991 e a previsão para o mesmo usando o polinômio do $2^{\circ}$ grau, o polinômio do $3^{\circ}$ grau e a forma funcional de Anand e Kanbur (1993), usando a Renda. A disposição dos pontos que representam os valores reais permite perceber o pouco poder explicativo dos modelos utilizados. Além disso, os resultados se assemelham mais a um J invertido (tal como observado por Deutsch e Silber, 2004) do que ao $\mathrm{U}$ invertido. A figura 2 mostra o índice $\mathrm{L}$ de Theil em 2000 e a previsão para o mesmo usando o polinômio do $2^{\circ}$ grau, o polinômio do $3^{\circ}$ grau e a forma funcional de Anand e Kanbur (1993), com a Renda. As curvas de valores previstos apresentam novamente o formato em J invertidos semelhantes, com exceção do caso do polinômio do $3^{\circ}$ grau, que apresenta uma parte convexa mais pronunciada. A aderência do modelo aos dados é limitada, novamente. 
Figura 1. Curvas de Kuznets para L de Theil usando Renda, 1991

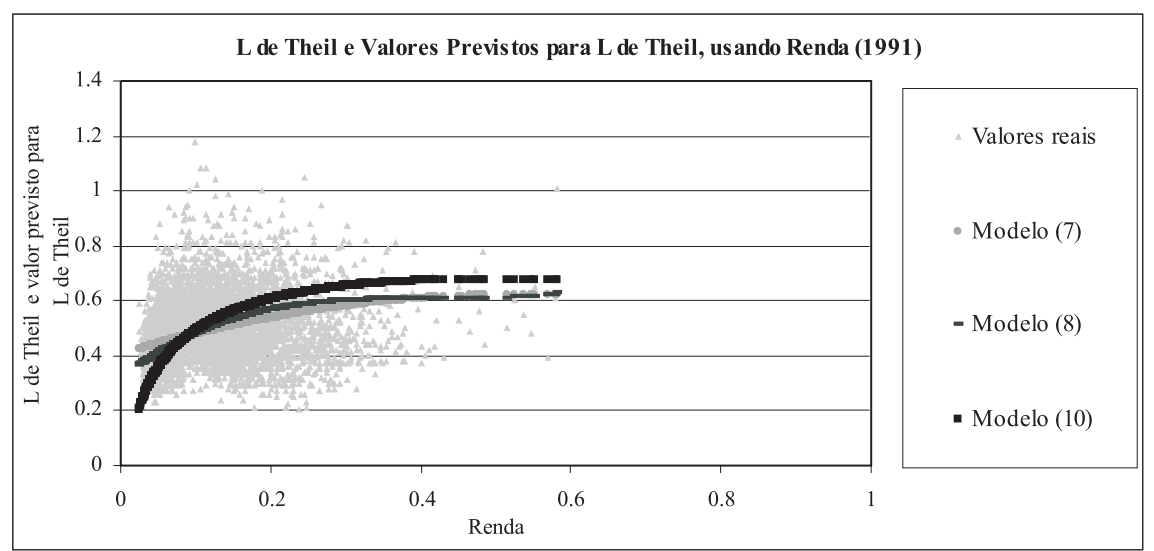

Fonte: Elaboração dos autores.

A figura 3 mostra as curvas estimadas a partir dos valores previstos do Gini para 1991 pelos modelos com Renda, sendo evidente o formato em "J" invertido, tal como pelos modelos para L de Theil em 1991. A disposição dos pontos que representam os valores reais permite perceber o pouco poder explicativo dos modelos utilizados. A figura 4 mostra o índice de Gini em 2000 e a previsão para o mesmo usando o polinômio do $2^{\mathrm{O}}$ grau, o polinômio do $3^{\circ}$ grau e a forma funcional de Anand e Kanbur (1993), com a Renda. Tal como ocorre com o L de Theil em 2000, as curvas de valores previstos apresentam novamente o formato em " $\mathrm{J}$ " invertidos semelhantes, excetuando-se o caso do polinômio do $3^{\circ}$ grau, que apresenta uma parte convexa mais pronunciada, tal como sugerido por List e Gallet (1999).

Figura 2. Curvas de Kuznets para L de Theil usando Renda, 2000

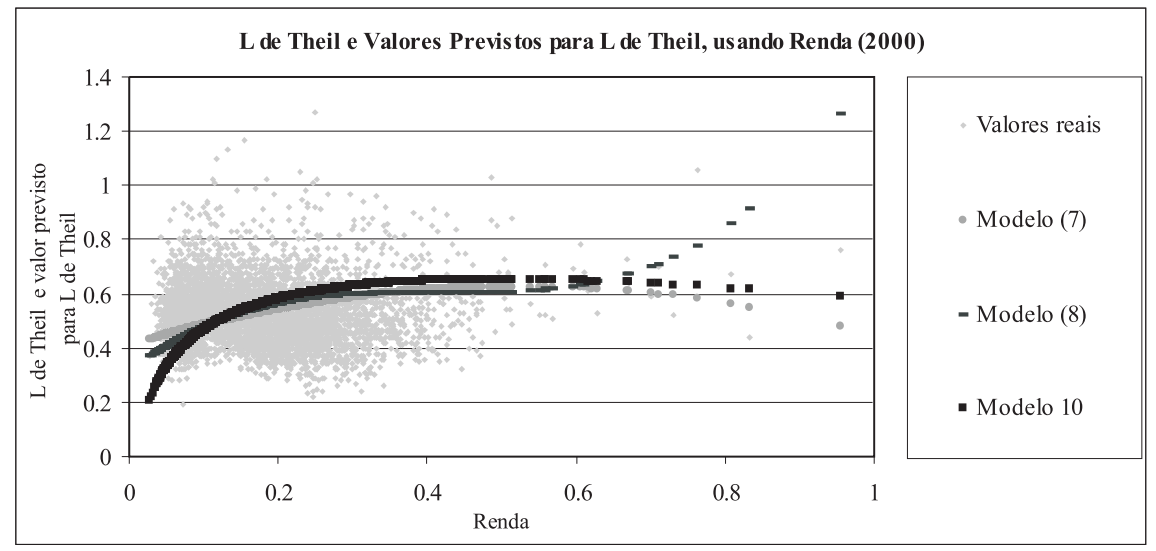

Fonte: Elaboração dos autores.

72 Revista Análise Econômica, Porto Alegre, ano 26, n. 50, p. 57-81, setembro de 2008. 
Figura 3. Curvas de Kuznets para Gini usando Renda, 1991

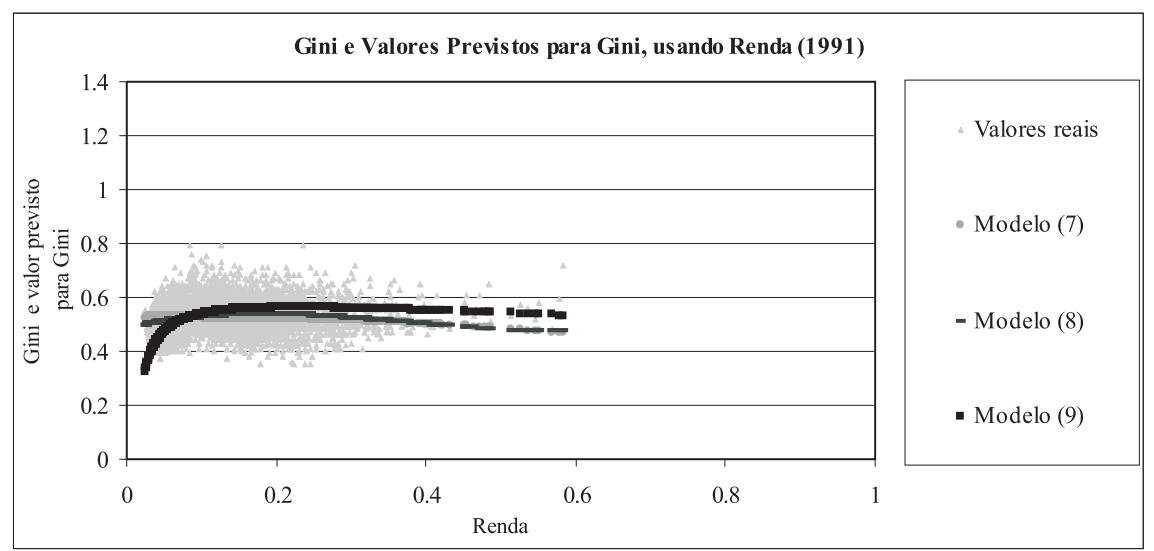

Fonte: Elaboração dos autores.

As figuras 5 a 8 apresentam os resultados das regressões das tabela 5 e 6. A figura 5 mostra o índice L de Theil em 1991 e a previsão para o mesmo usando o polinômio do $2^{\circ}$ e do $3^{\circ}$ grau, usando a Urbana. Observa-se o baixo poder explicativo dos modelos. A figura 6 mostra o índice L de Theil em 2000 e a previsão para o mesmo, com a variável Urbana. Os resultados são muito similares aos de 1991.

A figura 7 mostra as curvas traçadas a partir dos valores previstos do Gini em 1991 pelos modelos com a variável Urbana. As curvas estimadas não apresentam uma aderência razoável aos dados. A figura 8 mostra o índice de Gini em 2000 e a previsão para o mesmo usando a Urbana. Novamente, a capacidade explicativa limitada do modelo é bastante aparente.

Figura 4. Curvas de Kuznets para Gini usando Renda, 2000

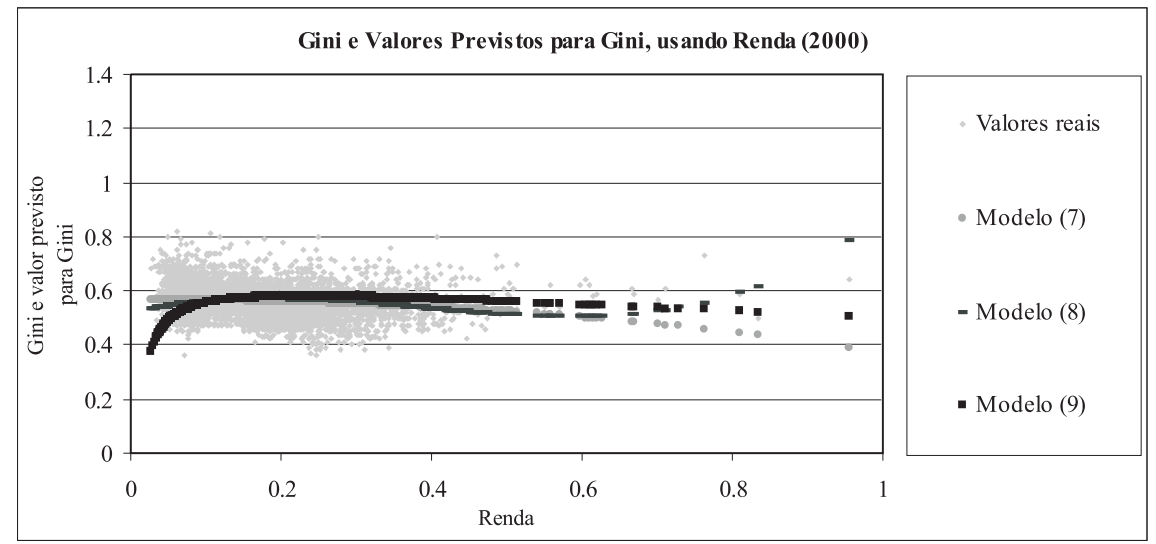

Fonte: Elaboração dos autores. 
Figura 5. Curvas de Kuznets para L de Theil usando Urbana, 1991

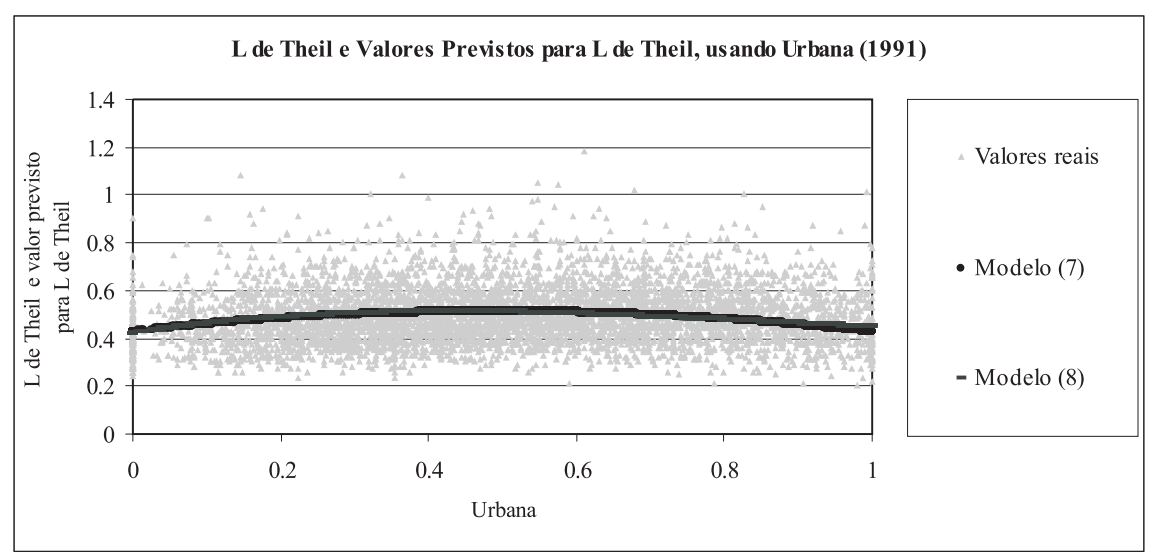

Fonte: Elaboração dos autores.

Figura 6. Curvas de Kuznets para L de Theil usando Urbana, 2000

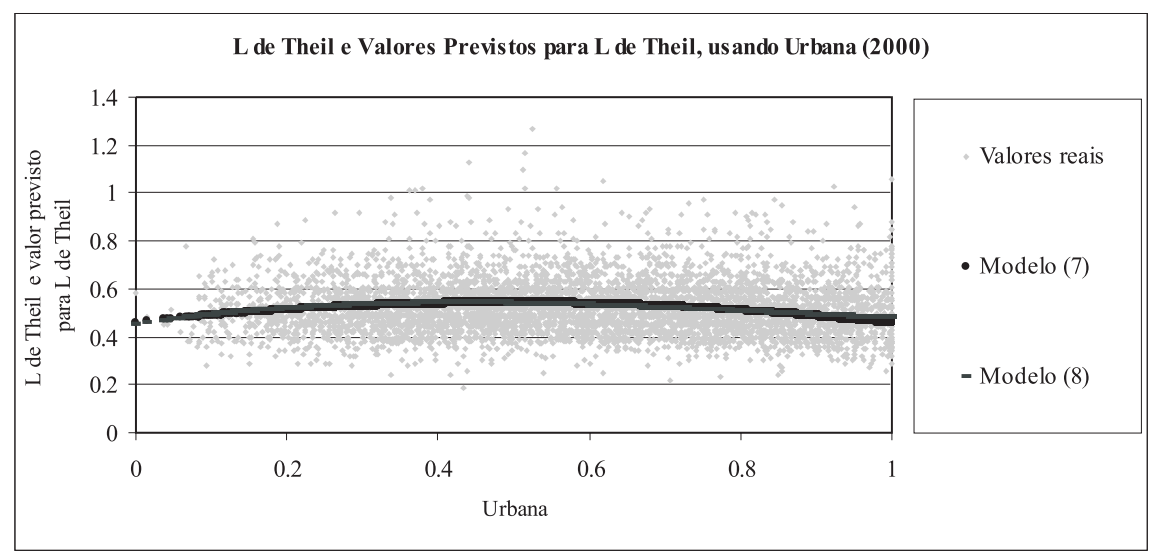

Fonte: Elaboração dos autores.

74 Revista Análise Econômica, Porto Alegre, ano 26, n. 50, p. 57-81, setembro de 2008. 
Figura 7. Curvas de Kuznets para Gini usando Urbana, 1991

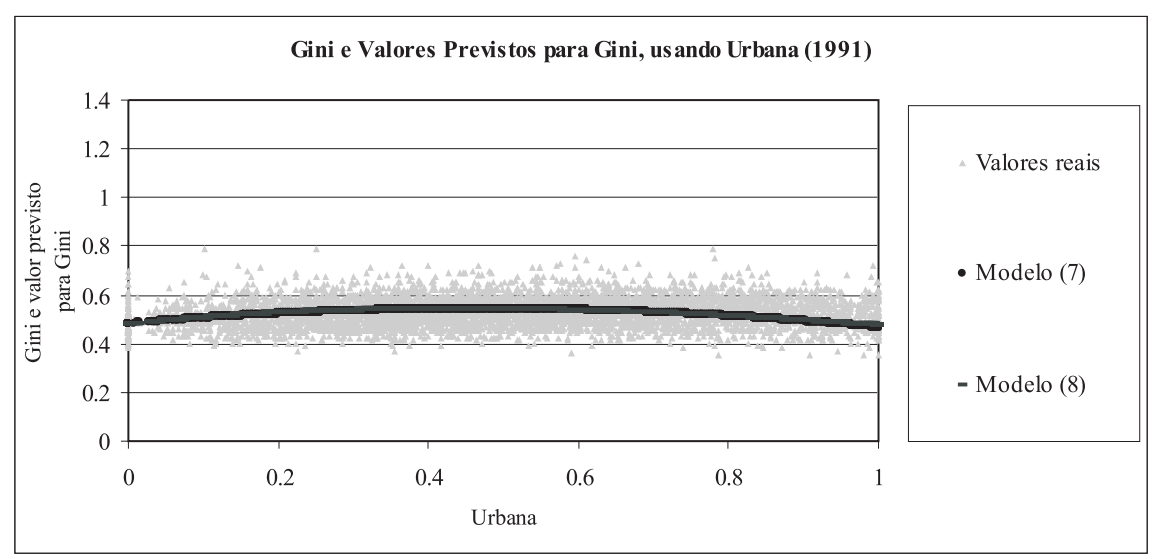

Fonte: Elaboração dos autores.

Figura 8. Curvas de Kuznets para Gini usando Urbana, 2000

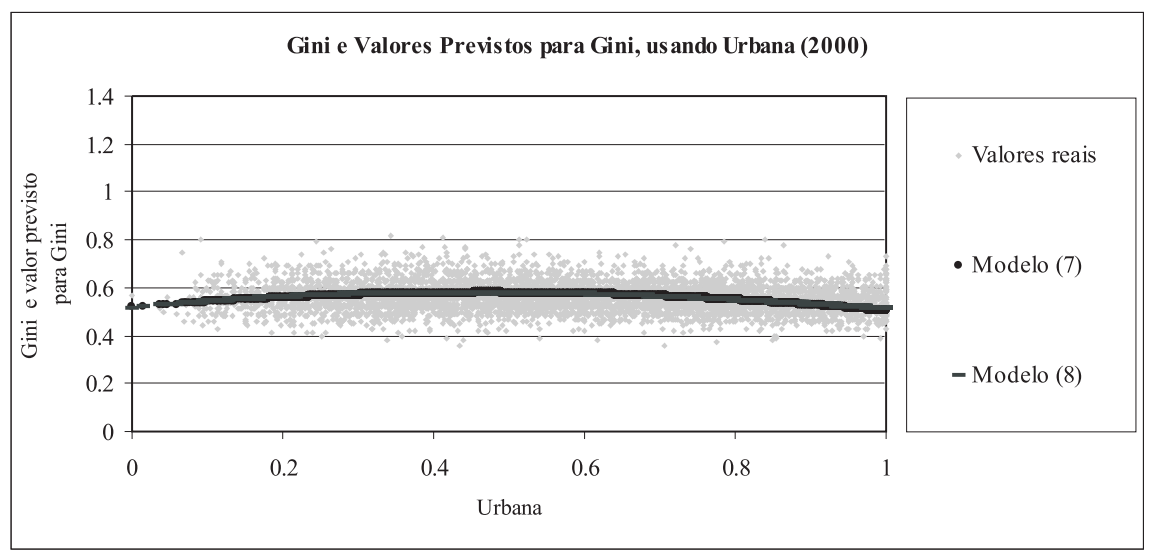

Fonte: Elaboração dos autores. 
Finalmente, considerando o polinômio do $3^{\circ}$ grau - o modelo mais geral por ser o único capaz de investigar tanto a hipótese de Kuznets (1955) quanto a de List e Gallet (1999) -, os resultados do modelo de EF são estes: i) ao combinar o Gini com Renda e o L de Theil com Renda ou Urbana, há evidência de que a relação entre desigualdade e desenvolvimento não é côncava; ii) a hipótese de Kuznets não é rejeitada apenas quando se usa o Gini com a variável Urbana, porém a análise do $\mathrm{R}^{2} \mathrm{e}$ a inspeção visual dos gráficos sugere que mesmo neste caso, a capacidade explicativa da hipótese de Kuznets é bastante limitada.

\section{Considerações Finais}

A Constituição Federal do Brasil de 1988 (art. $3^{\circ}$, inciso III) ressalta como um dos objetivos fundamentais da República Federativa do Brasil "erradicar a pobreza e a marginalização e reduzir as desigualdades sociais e regionais". Este objetivo será alcançado com sucesso após um diagnóstico claro da desigualdade de renda. Nesta perspectiva, o objetivo deste artigo foi precipitar este sucesso, ao investigar a desigualdade de renda entre os municípios brasileiros.

Assim, este trabalho analisou a validade da hipótese de Kuznets para 5.507 municípios brasileiros nos anos de 1991 e 2000. Após a estimação de diversas formas funcionais encontradas na literatura pesquisada conclui-se que há pouca evidência a favor dessa hipótese. Os modelos com polinômio de $2^{\circ}$ grau e forma funcional de Anand e Kanbur (1993) - para a renda - não rejeitam a hipótese de Kuznets. Porém, apresentam um poder explicativo bastante limitado. Porém, utilizando o modelo mais geral, isto é, o polinômio do $3^{\circ}$ grau (estimador de $\mathrm{EF}$ ), a predição de List e Gallet (1999) não é confirmada apenas quando se usa o Gini com a variável Urbana. Mas, mesmo neste caso o poder explicativo do modelo deixa a desejar. De todo modo, uma contribuição importante deste trabalho é a adição de uma nova variável representativa de "desenvolvimento econômico": a razão entre a população urbana e total, cujos resultados qualitativos foram diferentes da variável Renda no caso do polinômio do $3^{\circ}$ grau quando a desigualdade é medida pelo Gini.

Dada a importância do tema desigualdade e o poder explicativo limitado dos modelos empregados neste artigo, como tópico de pesquisa futura destaca-se a importância de se acoplar à curva de Kuznets (1955) e de List e Gallet (1999) outros modelos teóricos/variáveis explicativos que possam gerar uma melhor compreensão da 
desigualdade e de sua relação com o nível desenvolvimento da sociedade. Tal avanço poderá permitir a elaboração de políticas públicas mais eficazes no combate à desigualdade, residindo nesta possibilidade sua relevância. De fato, a desigualdade de renda, seja ela verificada dentro dos municípios ou entre os municípios, deve ser considerada nas etapas de planejamento de qualquer política pública.

\section{Referências Bibliográficas}

ANAND, S.; KANBUR, S.M.R. The Kuznets process and the inequality-development relationship. Journal of Development Economics, v. 40, p. 25-52, 1993.

ATLAS DO DESENVOLVIMENTO HUMANO. IPEA/FJP/PNUD, 2003.

BAGOLIN, I. P.; GABE, J.; RIBEIRO, I.P. Crescimento e Desigualdade no Rio Grande do Sul: uma revisão da Curva de Kuznets para os municípios gaúchos (1970-1991). Anais do $2^{\circ}$ Encontro de Economia Gaúcha 2004, Porto Alegre: realização PUCRS e Fundação de Economia e Estatística (FEE), 2004. Disponível em: < http://www.fee.rs.gov.br/sitefee/ download/eeg/2/2.4.zip >. Acesso em: 29 out. 2006.

BARRO, R. J. Inequality and growth in a panel of countries. Journal of Economic Growth, V. 5, p. 5-32, 2000.

BÊRNI, D. de Á.; MARQUETTI, A.; KLOECKNER, R. A desigualdade econômica do Rio Grande do Sul: primeiras investigações sobre a curva de Kuznets. Anais do $1^{\circ}$ Encontro de Economia Gaúcha 2004, Porto Alegre: realização PUCRS e Fundação de Economia e Estatística (FEE), 2002. Disponível em: <http:/www.fee.rs.gov.br/sitefee/download/eeg/ 1/mesa_3_berni_marquetti_kloeckner.pdf>. Acesso em: 29 out. 2006.

DEININGER, K.; SQUIRE, L. A new data set measuring income inequality. World Bank Economic Review, v. 10, p. 565-91, 1996.

DEUTSCH, J.; SILBER, J. The Kuznets curve and the impact of various income sources on the link between inequality and development. Working Paper, Bar-Ilan University, Israel, 2000. Disponível em: < http://www.biu.ac.il/soc/ec/wp/3-01/kuznets.pdf > . Acesso em: 15 ago. 2006.

GLAESER, E. L. Inequality. NBER Working Paper Series. Harvard Institute of Economic Research, NBER, and KSG Faculty Research Working Paper Series RWP05-056, October 2005. Disponível em: < http://papers.nber.org/papers/w11511.pdf> . Acesso em: 15 maio 2006.

JACINTO, P. de A.; TEJADA, C. A. O. Desigualdade de renda e crescimento econômico nos municípios da região nordeste do Brasil: O que os dados têm a dizer? Anais do XXXII Encontro Nacional de Economia [Proceedings of the 32th Brazilian Economics Meeting] 039, ANPEC - Associação Nacional do Centros de Pós-graduação em Economia [Brazilian Association of Graduate Programs in Economics], 2004. Disponível em: < http://www.anpec.org.br/encontro2004/artigos/A04A039.pdf > . Acesso em: 29 out. de 2006.

KUZNETS, S. Economic Growth and Income Inequality. American Economic Review, v. 65, p. 1-28, 1955.

LIN, Shu-Chin; HUANG Ho-Chuan; WENG, Hsiao-Wen. A semi-parametric partially linear investigation of the Kuznets' hypothesis. Journal of Comparative Economics, v. 34, p. 634-647, 2006. 
LIST, J. A.; GALLET, C. A. The Kuznet's curve: what happens after the inverted-U? Review of Development Economics, v. 3, p. 200-206, 1999.

LOPEZ, H. Growth and inequality: are the 1990s different? Economic Letters, v. 93, p. 1825, 2006.

MELTZER, A. H.; RICHARD, S. F. A Rational Theory of the Size of Government. Journal of Political Economy, v. 89, p. 914-927, 1981.

MUSHINSKI, D. W. Using non-parametrics to inform parametric tests of Kuznet's hypothesis. Applied Economic Letters, v. 8, p. 77-79, 2001.

SALVATO, M. A.; ALVARENGA, P. S.; FRANÇA, C. S.; ARAÚJO Jr., A. F. Crescimento e Desigualdade: evidências da Curva de Kuznets para os municípios de Minas Gerais - 1991/ 2000. Ibmec MG Working Paper - WP33, 2006. Disponível em: < http://www.ceaee. ibmecmg.br/wp/wp33.pdf> . Acesso em: 20 jun. 2006.

THORNTON, J. The Kuznets inverted-U hypothesis: panel data evidence from 96 countries. Applied Economics Letters, v. 8, p. 15-16, 2001.

VANHOUDT, P. An assessment of the macroeconomic determinants of inequality. Applied Economics, v. 32, p. 877-883, 2000.

VOITCHOKSY, S. Does the profile of income inequality matter for economic growth? Distinguishing between the effects of inequality in different parts of the income distribution. Journal of Economic Growth, v. 10, p. 273-296, 2005.

WOOLDRIDGE, J. M. Econometric Analysis of Cross Section and Panel Data, Cambridge, MA: MIT Press, 2001. 


\section{Anexos}

Tabela 2. Resultados para o Modelo (7), usando a Renda

\begin{tabular}{|c|c|c|c|c|c|c|}
\hline \multirow[b]{2}{*}{ Regressores } & \multicolumn{3}{|c|}{ Var. Dep.: L de Theil } & \multicolumn{3}{|c|}{ Var. Dep.: Gini } \\
\hline & POLS & EF & EA & POLS & EF & EA \\
\hline \multirow[t]{2}{*}{ Renda $\left(\alpha_{1}\right)$} & 0,1779 & 0,8328 & 0,2169 & $-0,0525$ & 0,0281 & $-0,0336$ \\
\hline & $-5,43$ & $-10,12$ & $-6,15$ & $(-3,13)$ & $-0,63$ & $(-1,87)$ \\
\hline \multirow{2}{*}{ Renda ao quadrado $\left(\alpha_{2}\right)$} & $-0,1685$ & $-0,7959$ & $-0,2057$ & 0,0356 & $-0,2185$ & $-0,0175$ \\
\hline & $(-2,29)$ & $(-6,09)$ & $(-2,69)$ & $-0,94$ & $(-3,08)$ & $(-0,45)$ \\
\hline \multirow[t]{2}{*}{ Dummy de tempo $(\delta)$} & 0,0255 & 0,0054 & 0,0243 & 0,0367 & 0,0374 & 0,0367 \\
\hline & $-11,44$ & $-1,99$ & $-13,56$ & $-32,14$ & $-25,16$ & $-38,28$ \\
\hline \multirow{2}{*}{ Constante $\quad\left(\alpha_{0}\right)$} & 0,4722 & 0,4045 & 0,4681 & 0,5317 & 0,527 & 0,5304 \\
\hline & $-152,64$ & $-50,77$ & $-140,13$ & $-335,23$ & $-121,74$ & $-312,1$ \\
\hline Condição de Concavidade é atendida? & SIM & SIM & SIM & NÃO & SIM & NÃO \\
\hline $\mathrm{N}^{\circ}$ de observações & 11014 & 11014 & 11014 & 11014 & 11014 & 11014 \\
\hline $\mathrm{R}^{2}$ & 0,0256 & 0,0821 & 0,0701 & 0,0864 & 0,2202 & 0,2183 \\
\hline Teste de Hausman (p-valor) & - & \multicolumn{2}{|c|}{$82,66(0,0000)$} & - & \multicolumn{2}{|c|}{$21,75(0,0001)$} \\
\hline \multicolumn{7}{|c|}{$\begin{array}{l}\text { Notas: O número de observações é igual a } 5.507 \text { para } 1991 \text { e } 2000 \text {. Renda é a renda per capita em } \mathrm{R} \$ 1000 \text {. A } \\
\text { estatística } t \text { está apresentada entre parênteses. Nos modelos de EF e EA o } \mathrm{R}^{2} \text { apresentado é o } \mathrm{R}^{2} \text { within. O teste de } \\
\text { Hausman rejeita o modelo de EA no caso do Gini e do L de Theil (entre parêntesis está o seu p-valor). }\end{array}$} \\
\hline
\end{tabular}

Fonte: Elaboração dos autores.

Tabela 3. Resultados para o Modelo (8), usando a Renda

\begin{tabular}{|c|c|c|c|c|c|c|}
\hline \multirow[b]{2}{*}{ Regressores } & \multicolumn{3}{|c|}{ Var. Dep.: L de Theil } & \multicolumn{3}{|c|}{ Var. Dep.: Gini } \\
\hline & POLS & EF & EA & POLS & EF & EA \\
\hline \multirow{2}{*}{ Renda $\left(\alpha_{1}\right)$} & 0,8929 & 2,1241 & 0,8974 & 0,2595 & 0,6711 & 0,3049 \\
\hline & $-13,29$ & $-15,45$ & $-13,16$ & $-7,52$ & $-8,97$ & $-8,65$ \\
\hline \multirow{2}{*}{ Renda ao quadrado $\left(\alpha_{2}\right)$} & $-3,263$ & $-5,1661$ & $-3,0763$ & $-1,3147$ & $-2,3947$ & $-1,4536$ \\
\hline & $(-12,33)$ & $-13,02$ & $(-11,92)$ & $(-9,67)$ & $(-11,09)$ & $(-10,8)$ \\
\hline \multirow{2}{*}{ Renda ao cubo $\left(\alpha_{3}\right)$} & 3,3692 & 4,1733 & 3,0639 & 1,4701 & 2,0782 & 1,5382 \\
\hline & $-12,17$ & $-11,65$ & $-11,63$ & $-10,34$ & $-10,65$ & $-11,14$ \\
\hline \multirow[t]{2}{*}{ Dummy de tempo $(\delta)$} & 0,0253 & $-0,0045$ & 0,0237 & 0,0366 & 0,0324 & 0,0365 \\
\hline & $-11,45$ & $(-1,59)$ & $-13,33$ & $-32,23$ & $-21,03$ & $-38,34$ \\
\hline \multirow[t]{2}{*}{ Constante $\left(\alpha_{0}\right)$} & 0,433 & 0,317 & 0,4299 & 0,5146 & 0,4834 & 0,5115 \\
\hline & $-97,23$ & $-29,14$ & $-92,04$ & $-224,97$ & $-81,62$ & $-213,5$ \\
\hline Condição de Concavidade é atendida? & NÃO & NÃO & NÃO & $\mathrm{NÃO}$ & $\mathrm{NA} O$ & $\mathrm{NÃO}$ \\
\hline $\begin{array}{l}\text { Em quantos municípios não foi atendida } \\
\text { em } 1991\end{array}$ & 82 & 20 & 65 & 132 & 28 & 96 \\
\hline $\begin{array}{l}\text { Em quantos municípios não foi atendida } \\
\text { em } 2000\end{array}$ & 362 & 88 & 305 & 536 & 145 & 418 \\
\hline $\mathrm{N}^{\circ}$ de observações & 11014 & 11014 & 11014 & 11014 & 11014 & 11014 \\
\hline $\mathrm{R}^{2}$ & 0,0386 & 0,1042 & 0,0798 & 0,0952 & 0,236 & 0,2309 \\
\hline Teste de Hausman (p-valor) & - & \multicolumn{2}{|c|}{$174,96(0,0000)$} & - & \multicolumn{2}{|c|}{$52,32(0,0000)$} \\
\hline
\end{tabular}

Fonte: Elaboração dos autores.

Barros, L.; Gomes F. Desigualdade e desenvolvimento: a hipótese de Kuznets... 
Tabela 4. Resultados para os Modelos (9) e (10), usando a Renda

\begin{tabular}{|c|c|c|c|c|c|c|}
\hline \multirow{2}{*}{ Regressores } & \multicolumn{3}{|c|}{ Var. Dep.: L de Theil } & \multicolumn{3}{|c|}{ Var. Dep.: Gini } \\
\hline & POLS & EF & EA & POLS & EF & EA \\
\hline \multirow{2}{*}{ Renda $\left(\beta_{1}\right)$} & $-0,3528$ & $-0,4708$ & $-0,396$ & $-0,1703$ & $-0,139$ & $-0,2063$ \\
\hline & $(-9,75)$ & $(-8,83)$ & $(-10,7)$ & $(-16,27)$ & $(-6,85)$ & $(-19,12)$ \\
\hline \multirow{2}{*}{ (In) Renda $\left(\beta_{2}^{L}\right)$} & 0,0723 & 0,233 & 0,0859 & - & - & - \\
\hline & $-13,57$ & $-22,98$ & $-15,49$ & - & - & - \\
\hline \multirow{2}{*}{ Inverso da Renda $\left(\beta_{2}^{G}\right)$} & - & - & - & $-0,0025$ & $-0,0075$ & $-0,0033$ \\
\hline & - & - & - & $(-15,89)$ & $(-26,84)$ & $(-20,56)$ \\
\hline \multirow{2}{*}{ Dummy de tempo $(\delta)$} & 0,0235 & $-0,0247$ & 0,02101 & 0,035 & 0,0175 & 0,03408 \\
\hline & $-10,66$ & $(-8,56)$ & -12 & $-30,91$ & $-11,56$ & $-36,74$ \\
\hline \multirow{2}{*}{ Constante $\quad\left(\beta_{0}\right)$} & 0,6977 & 1,0758 & 0,7338 & 0,5751 & 0,6275 & 0,5886 \\
\hline & $-42,58$ & $-38,45$ & $-43,39$ & $-191,52$ & $-148,74$ & $-193,89$ \\
\hline Condição de Concavidade é aceita? & SIM & SIM & SIM & SIM & SIM & SIM \\
\hline $\mathrm{N}^{\circ}$ de observações & 11014 & 11014 & 11014 & 11014 & 11014 & 11014 \\
\hline $\mathrm{R}^{2}$ & 0,0412 & 0,1568 & 0,1041 & 0,1069 & 0,3093 & 0,2796 \\
\hline Teste de Hausman (p-valor) & - & \multicolumn{2}{|c|}{$404,15(0,0000)$} & - & \multicolumn{2}{|c|}{$336,2(0,0000)$} \\
\hline \multicolumn{7}{|c|}{$\begin{array}{l}\text { Notas: O número de observações é igual a } 5.507 \text { para } 1991 \text { e } 2000 \text {. Renda é a renda per capita em R } \$ 1000 \text {. A } \\
\text { estatística } t \text { está apresentada entre parênteses. Nos modelos de EF e EA o } R^{2} \text { apresentado é o } R^{2} \text { within. O teste de } \\
\text { Hausman rejeita o modelo de EA no caso do Gini e do L de Theil (entre parêntesis está o seu p-valor). }\end{array}$} \\
\hline
\end{tabular}

Fonte: Elaboração dos autores.

Tabela 5. Resultados para o Modelo (7), usando a Urbana

\begin{tabular}{|c|c|c|c|c|c|c|}
\hline \multirow{2}{*}{ Regressores } & \multicolumn{3}{|c|}{ Var. Dep.: L de Theil } & \multicolumn{3}{|c|}{ Var. Dep.: Gini } \\
\hline & POLS & EF & EA & POLS & EF & EA \\
\hline \multirow[t]{2}{*}{ Urbana $\left(\alpha_{1}\right)$} & 0,2917 & 0,3368 & 0,3004 & 0,1692 & 0,261 & 0,1862 \\
\hline & $-17,02$ & $-12,13$ & $-16,93$ & $-19,37$ & $-17,75$ & $-20,48$ \\
\hline \multirow{2}{*}{ Urbana ao quadrado $\left(\alpha_{2}\right)$} & $-0,2522$ & $-0,3406$ & $-0,2622$ & $-0,1566$ & $-0,2765$ & $-0,1731$ \\
\hline & $(-16,12)$ & $(-11,35)$ & $(-16,02)$ & $(-19,64)$ & $(-17,4)$ & $(-20,68)$ \\
\hline \multirow[t]{2}{*}{ Dummy de tempo $(\delta)$} & 0,026 & 0,0296 & 0,026109 & 0,0328 & 0,0348 & 0,0327 \\
\hline & $-12,04$ & $-14,03$ & $-15,32$ & $-29,81$ & $-31,19$ & $-36,27$ \\
\hline \multirow{2}{*}{ Constante $\quad\left(\alpha_{0}\right)$} & 0,4249 & 0,4302 & 0,42378 & 0,4911 & 0,4831 & 0,4878 \\
\hline & $-100,46$ & $-58,23$ & $-96,54$ & $-227,88$ & $-123,43$ & $-217,31$ \\
\hline Condição de Concavidade é aceita? & SIM & SIM & SIM & SIM & SIM & SIM \\
\hline $\mathrm{N}^{\circ}$ de observações & 11014 & 11014 & 11014 & 11014 & 11014 & 11014 \\
\hline $\mathrm{R}^{2}$ & 0,0438 & 0,0844 & 0,0826 & 0,1147 & 0,2607 & 0,2551 \\
\hline Teste de Hausman (p-valor) & - & \multicolumn{2}{|c|}{$12,8(0,0071)$} & - & \multicolumn{2}{|c|}{$58,65(0,0000)$} \\
\hline \multicolumn{7}{|c|}{$\begin{array}{l}\text { Notas: O número de observações é igual a } 5.507 \text { para } 1991 \text { e } 2000 \text {. Renda é a renda per capita em } R \$ 1000 \text {. A } \\
\text { estatística } t \text { está apresentada entre parênteses. Nos modelos de EF e EA o } R^{2} \text { apresentado é o } R^{2} \text { within. O teste } \\
\text { de Hausman rejeita o modelo de EA no caso do Gini e do L de Theil (entre parêntesis está o seu p-valor). }\end{array}$} \\
\hline
\end{tabular}

Fonte: Elaboração dos autores. 
Tabela 6. Resultados para o Modelo (8), usando a Urbana

\begin{tabular}{|c|c|c|c|c|c|c|}
\hline \multirow{2}{*}{ Regressores } & \multicolumn{3}{|c|}{ Var. Dep.: L de Theil } & \multicolumn{3}{|c|}{ Var. Dep.: Gini } \\
\hline & POLS & EF & EA & POLS & EF & EA \\
\hline \multirow[t]{2}{*}{ Urbana $\left(\alpha_{1}\right)$} & 0,3564 & 0,473 & 0,3898 & 0,2256 & 0,3178 & 0,257 \\
\hline & $-8,94$ & $-8,84$ & $-10,05$ & $-11,11$ & $-11,21$ & $-12,83$ \\
\hline \multirow{2}{*}{ Urbana ao quadrado $\left(\alpha_{2}\right)$} & $-0,4065$ & $-0,7394$ & $-0,4849$ & $-0,2911$ & $-0,4426$ & $-0,3482$ \\
\hline & $(-4,65)$ & $(-5,39)$ & $(-5,55)$ & $(-6,54)$ & $(-6,09)$ & $(-7,75)$ \\
\hline \multirow{2}{*}{$\begin{array}{ll}\text { Urbana ao cubo }\left(\alpha_{3}\right) \\
\end{array}$} & 0,1011 & 0,2932 & 0,1495 & 0,0882 & 0,122 & 0,1171 \\
\hline & $-1,8$ & $-2,98$ & $-2,59$ & $-3,07$ & $-2,34$ & $-3,97$ \\
\hline \multirow{2}{*}{ Dummy de tempo $(\delta)$} & 0,025771 & 0,0293 & 0,0258 & 0,0326 & 0,0347 & 0,0325 \\
\hline & $-11,9$ & $-13,91$ & $-15,13$ & $-29,55$ & $-31,08$ & $-35,97$ \\
\hline \multirow[t]{2}{*}{ Constante } & 0,418744 & 0,4226 & 0,416 & 0,4857 & 0,4799 & 0,4816 \\
\hline & $-76,93$ & $-54,05$ & $-78,32$ & $-175,19$ & $-115,86$ & $-175,73$ \\
\hline Condição de Concavidade é atendida? & SIM & $\mathrm{NĀO}$ & SIM & SIM & SIM & $\mathrm{NÂO}$ \\
\hline $\begin{array}{l}\text { Em quantos municípios não foi atendida em } \\
1991\end{array}$ & - & 595 & - & - & - & 80 \\
\hline $\begin{array}{l}\text { Em quantos municípios não foi atendida em } \\
\qquad 2000\end{array}$ & - & 954 & - & - & - & 100 \\
\hline $\mathrm{N}^{\circ}$ de observações & 11014 & 11014 & 11014 & 11014 & 11014 & 11014 \\
\hline $\mathrm{R}^{2}$ & 0,0441 & 0,0858 & 0,084 & 0,1154 & 0,2614 & 0,2572 \\
\hline Teste de Hausman (p-valor) & - & \multicolumn{2}{|c|}{$14,35(0,0062)$} & - & \multicolumn{2}{|c|}{$48,63(0,0000)$} \\
\hline
\end{tabular}

Fonte: Elaboração dos autores. 
